\title{
LIST OF ILLUSTRATIONS
}

Figure 1.1 Hot Girls Wanted

Figure 2.1 Pam Koffler, Todd Haynes and Christine Vachon 37

Figure 3.1 Megan Ellison, founder and producer, Annapurna Pictures 55

Figure 4.1 The Hot Flashes (2013) was released through vigorous advance marketing and social media campaigns $\quad 78$

Figure 5.1 Agnes Bruckner in Anna Nicole

Figure 6.1 Amy Seimetz in The Off Hours

Figure 7.1 Isaiah Stone, Jennifer Lawrence and Ashlee Thomson in Winter's Bone

Figure 8.1 Maxine and Shirin in Appropriate Behavior 150

Figure 9.1 Kenya and single-sister friends in Something New 162

Figure 10.1 Monsoon Wedding: Ria confronts her attacker as her uncle looks on

Figure 11.1 John Corbett, Anthony Kandiotis and Nia Vardalos in My Big Fat Greek Wedding

Figure 12.1 In Eve's Bayou, Aunt Mozelle shares a memory with her precocious niece Eve

Figure 13.1 Radha Mitchell and Ally Sheedy in High Art

Figure 14.1 John Hawkes in Me and You and Everyone We Know 248

Figure 15.1 Michelle Williams and Lucy the dog in Wendy and Lucy 268

Figure 16.1 Laurie Simmons' photograph in Lena Dunham's film Tiny Furniture

Figure 17.1 Mark Duplass and Joshua Leonard in Humpday

Figure 18.1 Children of Srikandi 